\title{
Research Paper: \\ Comparing Biomechanical Risk Factors of Anterior Cruciate Ligament Injury of Elite Female Soccer Players During the Shearing Maneuver and Header on the Natural Grass and Artificial Turf
}

Yasamin Alipour Ataabadi ${ }^{1^{*}}$ (D) Heydar Sadeghi $^{2}$ (D) Mohammad Hosein Alizadeh $^{3}$ (D) Mehdi Khaleghi $^{4}$

1. PhD. Student of Sports Biomechanics, Department of Physical Education and Sports Sciences, Kharazmi University, Tehran, Iran.

2. Professor, Department of Health and Sport Medicin, Faculty of Physical Education and Sport Sciences, Kharazmi University, Tehran, Iran.

3. Professor, Department of Physical Education and Sports Sciences, Faculty of Physical Education and Sport Sciences, Tehran University, Tehran, Iran.

4. Assistant Professor, Department of Physical Education and Sports Sciences, Faculty of Physical Education and Sport Sciences, Kharazmi University,

Tehran, Iran.

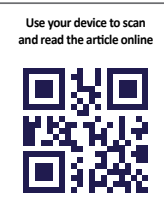

Citation Alipour Ataabadi Y, Sadeghi H, AlizadehMH, Khaleghi M. Comparing Biomechanical Risk Factors of Anterior Cruciate Ligament Injury of Elite Female Soccer Players During the Shearing Maneuver and Header on the Natural Grass and Artificial Turf. Journal of Exercise Science and Medicine (JESM). 2019; 11(1):51-60. http://dx.doi.org/10.32598/JESM.11.1.7

doi http://dx.doi.org/10.32598/JESM.11.1.7

\section{(i) $(9)$}

Article info:

Received: 01 Jun 2017

Accepted: 22 Aug 2017

Available Online: 01 Jan 2019

Keywords:

Anterior cruciate ligament, Artificial turf, Biomechanics, Cutting maneuver, Heading

\section{A B S T RACT}

Introduction: Nowadays, the use of artificial turf fields has become widespread. Given the high prevalence of noncontact injuries among female soccer players and high contribution of the Anterior Cruciate Ligament (ACL) injury, this research was conducted to compare biomechanical risk factors in the incidence of $\mathrm{ACL}$ injury for elite female soccer players during shearing maneuver and header on the natural grass and artificial turf fields.

Methods: Sixteen players were selected from U-14 women's national team by the convenience sampling method and started to perform the skills. Knee joint information was calculated by a 3D imaging system and a force plate. Statistical differences were reported using the dependent t-test at a significant level of 0.05 .

Results: The findings showed that the biomechanical behavior of the lower extremity while performing soccer skills on the natural grass was affected differently from that on the artificial turf. Results also demonstrated that the torque applied to the knee joint on the natural grass was higher than that on the artificial turf $(P=0.039)$. Angular velocity on the artificial turf was also higher than that on the natural grass $(P=0.006)$.

Conclusion: The higher knee joint torque and the lower angular velocity on natural grass may result in a higher risk of $\mathrm{ACL}$ injury on the natural grass than on the artificial turf. Therefore, the use of prevention programs for $\mathrm{ACL}$ injury is crucial to minimize the incidence of lower extremity injuries.

\section{* Corresponding Author:}

Yasamin Alipour Ataabadi, PhD.

Address: Department of Physical Education and Sports Sciences, Kharazmi University, Tehran, Iran.

Tel: +98 (913) 2134734

E-mail:yas.alipour@gmail.com 


\section{Introduction}

A nterior Cruciate Ligament $(\mathrm{ACL})$ tear is one of the most common knee injuries in sports, especially soccer $[1,2]$. Non-contact $\mathrm{ACL}$ injuries during stoppage, landing, and shearing maneuvers are common in exercises and sports competitions. Considering the high prevalence of ankle and knee injuries due to shearing and jumping motions in sports like soccer, the study of lower extremity joints while performing these skills could be beneficial to understand the risk factors of injuries. Most $A C L$ injuries are caused by activities such as running, jumping, and non-contact landing [3]. It has been reported that in most cases, the shearing maneuver is associated with a non-contact $A C L$ injury, especially during the single-leg landing step [4].

Studies show that the rate of $A C L$ injuries in female soccer players are higher than male players $[5,6]$.Women participating in exercises like jumping and shearing maneuvers are at higher risk of $A C L$ injury than men by eight times [7]. Since the deceleration rate required in the shearing maneuver depends on the velocity and the angle of maneuver, more torque, valgus, and medial rotation are applied to the knee, which could be increased up to twice in unforeseen circumstances [8].

Knee joint laxity in women is inherently and significantly higher; thus, a longer time is needed to detect knee joint movement toward the extension and, for joint stability, their hamstring activity is increased [9]. Moreover, among female soccer players, the rate of injuries in ankle and knee joints is higher than that in other areas [10]. Regarding the contact injuries in soccer, ligament sprain and muscular contusion are prevalent; male soccer players are more at the risk of an ankle sprain, while women often experience knee sprain. Also, the rate of $\mathrm{ACL}$ injury and fractures caused by compression forces are higher among women [6]. The most significant step in injury prevention is to identify its relevant risk factors. In this regard, researchers have classified risk factors for $\mathrm{ACL}$ injury into four main categories: anatomical, hormonal, environmental, and biomechanical factors [11, 12].Biomechanical factors are among changeable factors; therefore, many studies have been designed and implemented in this regard. Reports from the analysis of sports injury videotapes indicate that $A C L$ is mostly damaged during these two exercises: Jump-landing and shearing motions [13].

Playing surface is one of the factors affecting the athletes' performance. Nowadays, the use of artificial turf fields is increasing in various sports, especially soccer. More particularly, the use of third-generation artificial turf has become widespread, in which pieces of rubber and sand are used. Such turf has similar appearance and properties to natural grass, including the interaction between surface and ball, and between surface and shoes. Mechanical properties of artificial surfaces are related to sports injuries. Although, turf stiffness is affected by running, jumping, and landing on it [14], the risk of injury on more rigid or dry fields is higher [14].

Over time, the thickness of the layers of filler materials decreases; therefore, the turf becomes stiff, and the shock-absorbing layer becomes harder due to water damage. Shock reduction in the exercise surfaces plays a significant role in the incidence of injuries, especially in specific soccer activities such as running and jumplanding cycles in header and goalkeeping [15]. According to the studies, angular velocity is higher on artificial turf than on natural grass due to the higher stiffness of artificial turf. Stiff surfaces apply greater reaction force to the lower extremity of athletes, which could increase angular the velocity of the joints [16].

Artificial turf stiffness increases gradually, which increases the surface and shoe friction. Increased friction leads to reduced agility and a lower ability for fast change of direction on artificial surfaces. Therefore, the acceleration change rate on natural grass is higher than that on artificial turf [14]. Female athletes show lower performance in lower extremity agility and, during landing, their limb stiffness is higher. Reduced lower extremity agility and the compensatory mechanism of limb stiffness increase the risk of $A C L$ injuries among women [17].

Most sports injuries are related to ligament tear and fractures, which can lead to functional disability in the ankle and knee joints. Since the most crucial mechanism causing knee ligament injury is torque, it is essential to pay attention to this factor [18]. While performing these motions wearing spike shoes, natural grass generates higher torque peaks than artificial turf, which leads to rotational knee injuries, such as ACL [19].

Numerous researches have been conducted regarding the comparison of injuries on natural grass and artificial turf [20-22].According to their reports, thigh, knee, and ankle are the most vulnerable areas, and lower extremity injuries are higher on natural grass. In studies performed for comparing natural grass and artificial turf, soccer techniques have not been used and only general skills, such as running and jumping have been investigated. Thus, the present study aims to investigate the bio- 
mechanical risk factors of $A C L$ injury among elite female soccer players while performing a shearing maneuver and header on natural grass and artificial turf. Since it is not possible to measure these factors in turf fields, this study was carried out in the biomechanics laboratory and the performance information of the participants was recorded by putting pieces of natural grass and artificial turf on the force plate. Measuring these factors can provide further knowledge about biomechanical risk factors from a kinematic and kinetic perspective in the incidence of $A C L$ injury and help understand the probability of $A C L$ injury among female soccer players after using artificial turf compared to natural grass.

\section{Materials \& Methods}

\section{Participants and surfaces}

The statistical population of this research consisted of female soccer players. Sixteen players were selected from U-14 women's national team by a convenience sampling method, who at least had a history of two times of attendance in national team camps (Mean \pm SD age: $13.01 \pm 0.51$ years, Mean \pm SD height: $155 \pm 8.57 \mathrm{~cm}$ and weight Mean $\pm S D: 46.82 \pm 9.90 \mathrm{~kg}$ ). Then, the participants were informed about the goals of the research and testing method; ethical considerations were also considered. First, the participants were selected based on the research inclusion criteria: No injury in the last year, attending training sessions at least three times per week, full mastery of the skills used in this research, and being right-footed. Then, their anthropometric characteristics were measured.

To identify the dominant organ, they were asked to jump forward with one leg. The leg that they suddenly selected for the jump was considered the dominant leg. The study data were collected at Biomechanics Laboratory, Sharif University of Technology (Javad Movafaghian Research Centre of Intelligent Neuro-Rehabilitation Technologies). To perform motions similar to the exercise, the participants wore spike shoes; the spike length was $1 \mathrm{~cm}$. To avoid the effect of temporal factors on the test results, the measurement process was performed at the same time of the day. To prepare the conditions for the participants, a piece of Natural Grass (NG) (for soccer fields) with the size of $2 \mathrm{~m} \times 1 \mathrm{~m}$ and thickness of $5 \mathrm{~cm}$ and a third-generation Artificial Turf (AT) with rubber granules at the similar sizes and thickness of $3 \mathrm{~cm}$ were placed on a Kistler force plate $(50 \times 60)$ and firmly tightened by adhesive tape on the path surface. Paper adhesives on the turf determined the precise location of the force plate. It should be noted that techniques performed by the participants (shearing maneuver and landing after the header) were parts of the FIFA 11+ program and the participants were quite familiar with these skills. To increase the accuracy of the results, the participants performed each technique three times on each surface of natural grass and artificial turf. The participants were asked not to look at the force plate during the motions and to perform them naturally. After learning how to perform the exercise and several repetitions of the exercise, the researcher attempted to record the information by the force plate and camera.

\section{Data collection}

After selecting the participants based on the research inclusion criteria, proper clothing was prepared. Cleveland marker method was used and 11 reflective markers were placed on the anatomical landmarks of the lower extremity as follows: The first and fifth metatarsal, heel, medial and lateral malleolus, lateral epicondyle of the knee, medial and lateral epicondyles of the femur, greater trochanter, anterior superior iliac spine, and posterior superior iliac spine.

An 8-m route was considered to implement the skills, which was covered by the 6-camera 3D motion analysis system (Vicon, MX-T405). Two pieces of third-generation artificial turf and natural grass were randomly placed on the specified path for shearing maneuver. The movements consisted of $5 \mathrm{~m}$ of acceleration phase and, then, performing shearing maneuver ( $30^{\circ}$ angle shift) and landing after the header. In the shearing maneuver, the person moved straight and suddenly performed a shearing motion to her right side. In the header, the person moved straight and, then, performed a singleleg jump for header and landed on the force plate with the right foot. The rest of the path was used for the deceleration phase.

The angle of shearing maneuver was predetermined by the adhesives on the turf and grass that was visible. The participants performed the skills three times using their dominant leg, i.e. right foot. For recording the marker information, a 6-camera motion analysis system at the frequency of $120 \mathrm{~Hz}$ was used. Each marker was visible by at least two cameras. To record the kinetic information, a force plate at the frequency of $1200 \mathrm{~Hz}$ was employed. Due to the comparability of the participants' data, all data on angular velocity, angular acceleration, torque, and joint force, joint reaction force, segment energy, the center of pressure, and vertical ground reaction force were temporally normalized. To do so, the spline interpolation method to 100 normal data was used. 


\section{Data analysis}

In this research, the location data of markers and force plate $(x, y$, and $z$ coordinates, ground reaction force and center of pressure [CoP]) were used during the shearing maneuver and header exercises. The raw kinematic and kinetic data were transferred to MATLAB for further processing. The data were filtered using a zero-lag fourth-order low-pass Butterworth filter. The cutoff frequency was set at $8 \mathrm{~Hz}$ for camera data and $50 \mathrm{~Hz}$ for force plate data. Knee joint angles were calculated using marker coordinates in three sagittal, frontal, and horizontal planes. Then, the angular velocity and angular acceleration of this joint were calculated using the central derivative method, respectively. The linear acceleration and velocity for the center of mass of the leg segment were calculated using the central derivative. Afterward the internal torque and joint power and energy were calculated using an inverse dynamic method. All the above calculations were done from the toe-off moment to the middle stance. Newton threshold of 10 was used to determine the contact moment with the force plate. Mean and the standard deviation was employed to describe data and, after determining data normality by the Kolmogorov-Smirnov test, the dependent $t$-test was used at the significance level of $\mathrm{P}<0.05$.

\section{Results}

Figure 1 shows the diagram of changes in angular velocity and acceleration during the shearing maneuver and header on two surfaces of natural grass and
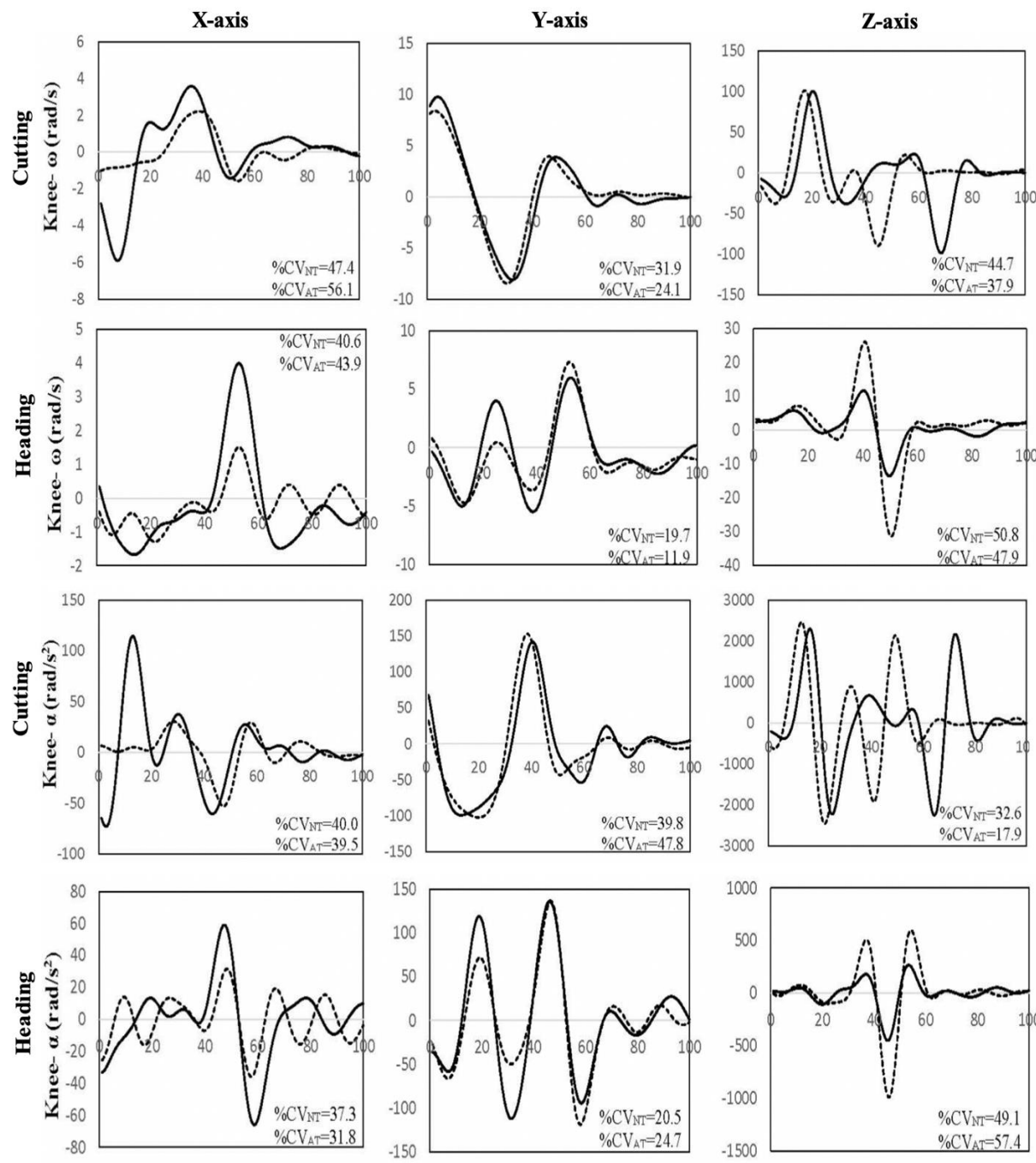

Figure 1. Diagrams of angular velocity and acceleration during the shearing maneuver and header in the $x$-axis (sagittal plane), $y$-axis (frontal plane), and z-axis (horizontal plate) on the Natural Grass (NG) and Artificial Turf (AT) 
Table 1. Mean $\pm S D$ and the significance level of the dependent $t$ test of angular velocity and acceleration of knee joint on the natural grass and artificial turf

\begin{tabular}{|c|c|c|c|c|c|c|c|}
\hline \multirow{3}{*}{$\begin{array}{l}\text { Vari- } \\
\text { able }\end{array}$} & \multicolumn{7}{|c|}{ Mean \pm SD } \\
\hline & \multirow{2}{*}{$\begin{array}{c}\text { Level } \\
\text { Task }\end{array}$} & \multicolumn{2}{|c|}{ X-axis (Sagittal Plane) } & \multicolumn{2}{|c|}{ Y-axis (Frontal Plane) } & \multicolumn{2}{|c|}{ Z-axis (Horizontal Plane) } \\
\hline & & Normal & Artificial & Normal & Artificial & Normal & Artificial \\
\hline \multirow{4}{*}{ 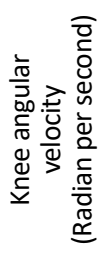 } & $\begin{array}{l}\text { Shearing } \\
\text { maneuver }\end{array}$ & $1.71 \pm 0.81$ & $1.55 \pm 0.87$ & $3.81 \pm 1.22$ & $4.15 \pm 1.00$ & $64.78 \pm 28.98$ & $86.17 \pm 32.73$ \\
\hline & Sig. & \multicolumn{2}{|c|}{0.074} & \multicolumn{2}{|c|}{0.006} & \multicolumn{2}{|c|}{0.001} \\
\hline & $\begin{array}{l}\text { Header } \\
\text { maneuver }\end{array}$ & $2.06 \pm 0.84$ & $1.72 \pm 0.75$ & $5.84 \pm 1.15$ & $6.25 \pm 0.74$ & $25.30 \pm 12.86$ & $27.91 \pm 13.37$ \\
\hline & Sig. & \multicolumn{2}{|c|}{0.227} & \multicolumn{2}{|c|}{0.119} & \multicolumn{2}{|c|}{0.543} \\
\hline \multirow{4}{*}{ 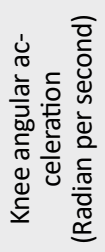 } & $\begin{array}{l}\text { Shearing } \\
\text { maneuver }\end{array}$ & $61.52 \pm 24.62$ & $38.34 \pm 15.14$ & $126.79 \pm 50.54$ & $109.73 \pm 52.41$ & $1983.47 \pm 646.98$ & $2396.60 \pm 430.25$ \\
\hline & Sig. & \multicolumn{2}{|c|}{0.033} & \multicolumn{2}{|c|}{0.833} & \multicolumn{2}{|c|}{0.833} \\
\hline & $\begin{array}{l}\text { Header } \\
\text { maneuver }\end{array}$ & $44.02 \pm 16.43$ & $37.45 \pm 11.93$ & $109.61 \pm 22.46$ & $110.27 \pm 27.24$ & $562.14 \pm 275.79$ & $521.16 \pm 299.23$ \\
\hline & Sig. & \multicolumn{2}{|c|}{0.201} & \multicolumn{2}{|c|}{0.907} & \multicolumn{2}{|c|}{0.498} \\
\hline
\end{tabular}

Exercise Science and Medicine
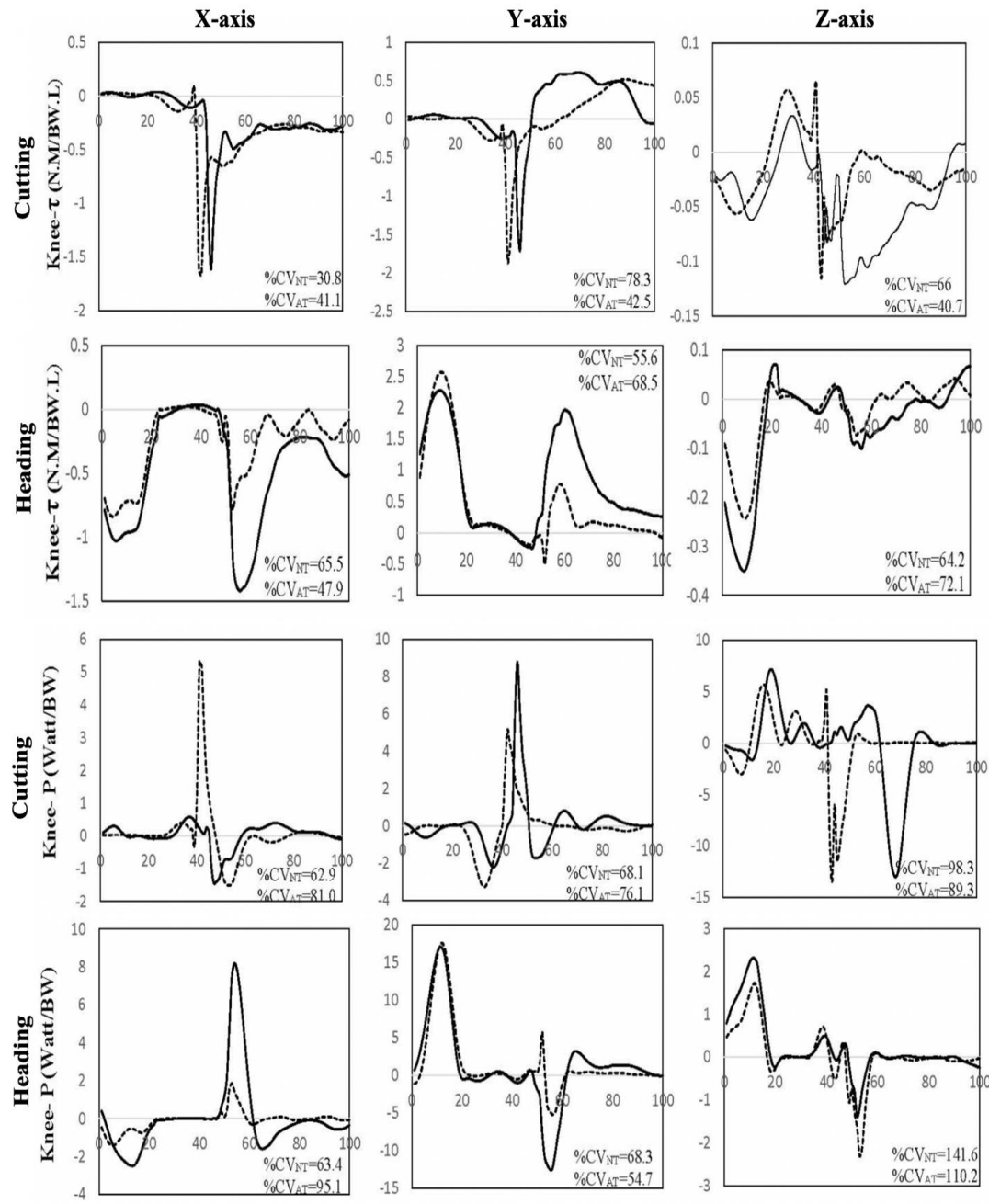

Journal of

Exercise Science and Medicine

Figure 2. Diagrams of torque and knee joint power during shearing maneuver and header in the x-axis (sagittal plane), $y$-axis (frontal plane), and z-axis (horizontal plane) on the Natural Grass (NG) and Artificial Turf (AT) 
Table 2. Mean $\pm S D$ and the significance level of the dependent $t$ test of torque and knee joint power ion the natural grass and artificial turf

\begin{tabular}{|c|c|c|c|c|c|c|c|}
\hline \multirow{3}{*}{ Variable } & \multicolumn{7}{|c|}{ Mean $\pm S D$} \\
\hline & \multirow{2}{*}{$\begin{array}{l}\text { Level } \\
\text { Task }\end{array}$} & \multicolumn{2}{|c|}{ X-axis (Sagittal Plate) } & \multicolumn{2}{|c|}{ Y-axis (Frontal Plate) } & \multicolumn{2}{|c|}{ Z-axis (Horizontal Plate) } \\
\hline & & Normal & Artificial & Normal & Artificial & Normal & Artificial \\
\hline \multirow{4}{*}{$\begin{array}{l}\text { Knee joint torque } \\
\text { (Newton per } \\
\text { meter) }\end{array}$} & $\begin{array}{l}\text { Shearing } \\
\text { maneuver }\end{array}$ & $1.11 \pm 0.34$ & $1.01 \pm 0.42$ & $0.95 \pm 0.74$ & $1.10 \pm 0.47$ & $0.18 \pm 0.06$ & $0.10 \pm 0.04$ \\
\hline & Sig. & \multicolumn{2}{|c|}{0.057} & \multicolumn{2}{|c|}{0.858} & \multicolumn{2}{|c|}{0.039} \\
\hline & $\begin{array}{l}\text { Header ma- } \\
\text { neuver }\end{array}$ & $0.67 \pm 0.44$ & $0.94 \pm 0.45$ & $1.30 \pm 0.73$ & $1.17 \pm 0.80$ & $0.06 \pm 0.04$ & $0.09 \pm 0.06$ \\
\hline & Sig. & \multicolumn{2}{|c|}{0.084} & \multicolumn{2}{|c|}{0.662} & \multicolumn{2}{|c|}{0.061} \\
\hline \multirow{4}{*}{$\begin{array}{l}\text { Knee joint power } \\
\text { (Watt) }\end{array}$} & $\begin{array}{l}\text { Shearing } \\
\text { maneuver }\end{array}$ & $1.15 \pm 0.49$ & $1.77 \pm 1.43$ & $\begin{array}{c}4.28 \\
\pm 2.91\end{array}$ & $4.75 \pm 3.61$ & $3.01 \pm 2.06$ & $3.26 \pm 2.91$ \\
\hline & Sig. & \multicolumn{2}{|c|}{0.373} & \multicolumn{2}{|c|}{0.059} & \multicolumn{2}{|c|}{0.126} \\
\hline & $\begin{array}{l}\text { Header ma- } \\
\text { neuver }\end{array}$ & $1.04 \pm 0.66$ & $1.32 \pm 1.06$ & $8.38 \pm 5.31$ & $7.30 \pm 3.99$ & $1.16 \pm 0.64$ & $2.28 \pm 1.51$ \\
\hline & Sig. & \multicolumn{2}{|c|}{0.955} & \multicolumn{2}{|c|}{0.791} & \multicolumn{2}{|c|}{0.028} \\
\hline
\end{tabular}

artificial turf. Table 1 presents the mean and standard deviation, as well as the dependent t-test results. As in Figure 1, the peaks of angular velocity and acceleration of the joints during the shearing maneuver and header on natural grass were higher than those on artificial turf. However, the average angular velocity and acceleration on artificial turf were higher than those on natural grass. The angular velocity in the knee joint in both frontal (7\%) and horizontal (32\%) planes during the shearing maneuver was greater on the artificial turf. In the header, the angular velocity was higher on the artificial turf in the frontal (7\%) and horizontal (10\%) planes, but sagittal angular velocity (21\%) was higher on the natural grass. The mean and standard deviation of the angular acceleration of the knee joint during shearing maneuver and header on both natural grass and artificial turf are presented in Table 1. Given the results, in the shearing maneuver, the angular acceleration values of sagittal $(60 \%)$ and frontal (15\%) planes were higher on the natural grass, but the angular horizontal acceleration (20\%) was higher on the artificial turf. In the header, the sagittal (17\%) and horizontal (7\%) angular acceleration values were higher on the natural grass and only frontal angular acceleration (8\%) on the artificial turf was higher than that on the natural grass.

Figure 2 shows the changes in torque and knee joint power during the shearing maneuver and header on two surfaces of natural grass and artificial turf and in three sagittal, frontal, and horizontal planes. As can be observed, while performing the shearing maneuver, the knee joint torque values in the sagittal (9\%) and horizontal (80\%) planes were higher on the artificial turf. Similar to torque, the power peaks were higher on the natural grass, except for the power of sagittal (40\%) plane, which was significantly higher on the artificial turf than on the natural grass. During the header, similar to the shearing maneuver, the peaks of knee joint torque in all three planes on the natural grass were higher than those on the artificial turf. The power of the knee joint in all planes showed higher peaks on the natural grass than artificial turf (Table 2).

\section{Discussion}

This study aimed to compare the biomechanical risk factors in the incidence of $A C L$ injury among elite female soccer players during shearing maneuver and header on the natural grass and artificial turf. Comparison results of the angular velocity of joints on the natural grass and artificial turf showed a significant difference in frontal and horizontal planes during a shearing maneuver in the knee joint so that artificial turf significantly increased angular velocity of the knee joint during the shearing maneuver. There are few studies on the kinematic analysis of the artificial surfaces. These findings have confirmed the results of previous studies about increased velocity on harder surfaces [16, 23].

Hardin et al. showed that higher surface stiffness led to increasing angular velocity of the knee and ankle joint [24]. Arianasab et al. found that angular velocity on the artificial turf was higher than that on the natural grass [16]. The probable cause of this matter could be the higher stiffness of artificial turf than natural grass. The stiff surfaces apply a higher reaction force to the lower extremity of the athlete that leads to an increased an- 
gular velocity of the joints. More angular velocity of the joints causes motions with higher angular momentum. Angular momentum plays a major role in dynamic balance and motion control. This means that an increase in angular torque occurs when the risk of injury is lower and the body uses less precaution to perform motions [25]. In contrast, on the natural grass, more control is applied to maintain dynamic stability, and, as a result, angular velocity decreases. Therefore, players are less concerned in the artificial turf and have less caution while performing moves in comparison to natural grass and have more angular velocity performance. This finding agrees with the results of studies that compare the satisfaction level of players in exercise on the natural grass and artificial turf. In these studies, young and semi-professional players, in contrast to professional and adult soccer players, have a higher tendency to play on artificial surfaces.

Biorillo et al. [26] evaluated the perception and satisfaction of semi-professional players with artificial turf. Their results showed that three-quarters of the players had a high satisfaction score with artificial turf. The most important advantage of artificial turf is the surface uniformity and greater comfort. In the study for surveying amateur players, Zanetti et al. [27] reported that the mean scores given by players indicated that artificial turf was better than natural grass only with the exception that there was a risk of abrasion in some of these fields. Moreover, for evaluating the prevalence of injuries on the natural grass and artificial turf, the results demonstrated that the injury rate among U-14 players and women on the artificial turf was lower than that on the natural grass $[28,29]$. Therefore, artificial turf is a safe surface for this group. This could be due to the low injury rate, especially the contact injuries among young soccer players. After assessing the prevalence of injuries during exercise and competition on the artificial turf, Bianco et al. [28] concluded that, in youth professional soccer, the rate of injuries on the artificial turf was reasonably low and artificial turf had no role in the prevalence of injuries among young soccer players.

Okan et al. [29] asked 11- to 15-year-old players about injuries, ground surface, type of shoes, and position to describe the acute injuries of the lower extremity and to evaluate exterior risk factors among young female soccer players. The results showed that the number of people injured on the natural grass was three times higher than that on the artificial turf. Also, Mir et al. [30] investigated the prevalence, mechanism, and severity of injuries related to the competition of female soccer players on the artificial turf compared to the natural grass and the results indicated a lower rate of injury and fewer contact injuries on the artificial turf. They stated that although there were similarities between the artificial turf and natural grass, artificial turf was a good alternative to reduce injury among female soccer players. Therefore, results of this study on the higher angular velocity of joints among female young soccer players on artificial turf indicated that the probability of injury on the artificial turf was lower than that on the natural grass and players were more assured in exercises on artificial surfaces. However, it should be noted that due to higher angular momentum in case of an injury on artificial turf, more severe injuries are expected on the artificial turf than natural grass. Therefore, this issue should be considered in exercise on artificial turf.

Comparison results of the angular velocity of joints on the natural grass and artificial turf showed no significant difference between the angular velocity of the knee joint in any plane while performing a header. For the assessment of angular acceleration of the joints at two surfaces of natural grass and artificial turf, the results showed that angular acceleration values of the knee joints in the sagittal and frontal planes during shearing maneuver were higher than the natural grass and such differences became significant only on the sagittal plane. In agreement with these findings, McLaren et al. [14] stated that stiffness of artificial surfaces would increase over time, which amplifies the surface and shoe friction. This increase in friction led to lower agility and the ability for fast change of direction on the artificial surfaces. Therefore, the acceleration rate on natural grass was higher than that on the artificial turf. This increase in angular acceleration can increase torque as well as the risk of injury.

Lyle et al. [17] showed that women were at higher risk of $\mathrm{ACL}$ injury than men and their lower extremity biomechanics increased their risk of injury during exercise maneuvers. Female athletes showed lower performance in lower extremity agility and stiffness of their limbs was higher during landing. Lower extremity agility and compensatory mechanism of limb tightening increase the risk of ACL injury among women. Comparison results of the joint's angular acceleration on the natural grass and artificial turf showed no significant difference between the angular acceleration of the knee joints during the header in any of the planes. These findings were consistent with the results obtained by Brachet et al. [31]. They stated no significant difference between the acceleration of the leg and thigh segments on the natural grass and third-generation artificial turf. Many sports injuries are related to ligament tear and fracture lead- 
ing to functional disability in ankle and knee joints. Since the most important mechanism for producing knee ligament injury is torque, thus, it is of great importance to pay attention to this factor [18].

Regarding the comparison of joint torque during a shearing maneuver on two surfaces of natural grass and artificial turf, the results showed the torque of the planes in the knee joint on the natural grass, but the difference became statistically significant only in the horizontal torque ( $P=0.039)$. Cawely et al. [19] showed that, in the performance of moves by spike shoes, the natural grass produced higher torque peaks than the artificial turf. They said that this condition would result in torsion injuries, such as ACL. Hence, their results confirmed the findings of the present study based on the higher torque of joints on the natural grass than artificial natural. Therefore, one of the important results of this research could be the higher values of knee torque on the natural grass compared to artificial turf. In this regard, Scranton et al. [32] investigated the non-contact $A C L$ injuries during five seasons and their results indicated a higher rate of injury on the natural grass than on the artificial turf.

In the research carried out by Strutzenberger et al. [33] on the $30^{\circ}$ and $60^{\circ}$ shearing maneuvers on the thirdgeneration artificial turf and natural grass, a decrease in the valgus knee and internal rotation were observed on the artificial turf that indicated the reduced risk of a knee injury. These data highlighted the point that artificial turf was no worse than natural grass and had the potential to reduce knee injuries. Therefore, the results of this study showed that, while performing shearing maneuvers, despite the higher stiffness of the artificial turf, the torque applied to the lower extremity joints on the natural grass was higher than that on the artificial turf. One of the reasons for higher values detected on the natural grass could be the compensatory reactions of the body in dealing with surfaces with various stiffness. Also, the results of the knee joint torque examination confirmed the results obtained in previous research about higher rates of injury on the natural grass than on the artificial turf [34-36].

After comparing knee torque during a header in two surfaces of natural grass and artificial turf, the results showed no significant difference. This research on the comparison of joints during a shearing maneuver in two surfaces of natural grass and artificial turf showed that the values of knee joint power in all three motion planes on the artificial turf were higher than those on the natural grass. These findings agreed with the findings of $\mathrm{Ha}-$ vens and Sigward [23]. Also, this pattern was similar to the results observed during direct running. In the above study, the players performed maneuvers on the force plate. They showed that the positive thigh power on the frontal plane and high values of this joint torque indicates that the thigh joint in the frontal plane during a shearing maneuver acts more like a stabilizer than making progress. The results of this study showed that knee power was negative on both surfaces. This finding is in contrast with the results of the study by Havens and Sigward [23], which showed a high negative force in the ankle and positive sagittal power in the knee. The possible cause of this inconsistency can be attributed to the surface difference, on which shearing maneuvers are performed. Therefore, this research showed that while performing shearing maneuvers, the power applied to the knee on the natural grass is higher than that on the artificial turf. This study compared joint power during header in two surfaces of natural grass and artificial turf showed that the knee joint power values in the sagittal and horizontal planes were higher on the artificial turf. In contrast, the values of natural grass were higher in the frontal plane. However, none of these differences were statistically significant. In the knee joint, the power peaks were negative in all three planes. This indicates the absorption of power by the knee joint. These findings are consistent with the study by Teixeira et al. [37], who stated that the joints were absorbing and working negatively from the moment of foot-ground contact. Negative muscle work reduced the load applied to the leg.

\section{Conclusion}

According to the results of this study, the biomechanical behavior of lower extremity is affected while performing soccer skills on the natural grass (softer surface) differently from the artificial turf (stiffer). The results showed that the knee joint angular velocity on the artificial turf was higher than that on the natural grass. On the natural grass, due to a higher probability of injury, the mechanism of dynamic balance control increases, and the angular momentum and, consequently, angular velocity reduces. Moreover, the results showed that the acceleration rate on the natural grass was higher than that on the artificial turf. This increase in the angular acceleration is associated with higher torque peaks on the natural grass, leading to torsion knee injuries, such as ACL. This research confirmed the studies carried out on a higher rate of $A C L$ injury on the natural grass than the artificial turf. Therefore, according to the results obtained in this study, the use of artificial turf in exercise reduces the risk of $A C L$ injury among young soccer play- 
ers. Also, the exercise is done with less assurance and risk on the artificial turf by players in this age category. Thus, it can lead to more exercise achievements. However, this greater assurance and performance at higher angular velocity are associated with the challenge of having a non-standard surface or low skill experience of players can lead to more severe injuries. Therefore, these cases should also be considered to determine the definitive effect of the surface on biomechanical risk factors at risk of $\mathrm{ACL}$ injury.

\section{Ethical Considerations}

\section{Compliance with ethical guidelines}

All ethical principles are considered in this article. The participants were informed about the purpose of the research and its implementation stages; they were also assured about the confidentiality of their information; moreover, they were free to leave the study whenever they wished, and if desired, the research results would be available to them.

\section{Funding}

This research did not receive any grant from funding agencies in the public, commercial, or non-profit sectors.

\section{Authors' contributions}

All authors were equally contributed in preparing this article.

\section{Conflict of interest}

The authors declared no conflict of interest.

\section{Reference}

[1] McCarthy MM, Voos JE, Nguyen JT, Callahan L, Hannafin JA. Injury profile in elite female basketball athletes at the Women's National Basketball Association combine. The American Journal of Sports Medicine. 2013; 41(3):645-51. [DOI:10.1177/0363546512474223] [PMID]

[2] Yu B, Garrett WE. Mechanisms of non-contact ACL injuries. British Journal of Sports Medicine. 2007; 41(suppl 1):i47-i51. [DOI:10.1136/ bjsm.2007.037192] [PMID] [PMCID]

[3] Boden BP, Dean GS, Feagin JA, Garrett WE. Mechanisms of anterior cruciate ligament injury. Orthopedics. 2000; 23(6):573-8. [DOI:10.3928/0147-7447-20000601-15] [PMID]
[4] Horino H. Sport injuries in female soccer players. Paper presented at: $6^{\text {th }}$ World Congress on Science and Football. 15-20 January 2007; Antalya, Turkey.

[5] Lindenfeld T, Schmitt D, Hendy M, Mangine R, Noyes F. Incidence of injury in indoor soccer. Journal of Safety Research. 1996; 1(27):58. [DOI:10.1016/0022-4375(96)86063-4]

[6] Mandelbaum B, Putukian M. Medical concerns and specificities in female soccer players. Science \& Sports. 1999; 14(5):254-60. [DOI:10.1016/S0765-1597(00)88245-3]

[7] Wojtys EM, Huston LJ, Schock HJ, Boylan JP, Ashton-Miller JA. Gender differences in muscular protection of the knee in torsion in size-matched athletes. Journal of Bone \& Joint Surgery (JBJS). 2003 85(5):782-9. [DOI:10.2106/00004623-200305000-00002] [PMID]

[8] Besier T, Lloyd D, Ackland T, Cochrane J. Anticipatory effects on knee joint loading during running and cutting maneuvers. Medicine and Science in Sports and Exercise. 2001; 33(7):1176-81. [DOI:10.1097/00005768-200107000-00015] [PMID]

[9] Rozzi SL, Lephart SM, Gear WS, Fu FH. Knee joint laxity and neuromuscular characteristics of male and female soccer and basketball players. The American journal of Sports Medicine. 1999; 27(3):312 9. [DOI:10.1177/03635465990270030801] [PMID]

[10] Engström B, Johansson C, Tornkvist H. Soccer injuries among elite female players. The American Journal of Sports Medicine. 1991; 19(4):372-5. [DOI:10.1177/036354659101900408] [PMID]

[11] Griffin LY, Agel J, Albohm MJ, Arendt EA, Dick RW, Garrett WE, et al. Noncontact anterior cruciate ligament injuries: Risk factors and prevention strategies. Journal of the American Academy of Orthopaedic Surgeons (JAAOS). 2000; 8(3):141-50. [DOI:10.5435/00124635200005000-00001] [PMID]

[12] Huston LJ, Greenfield MLV, Wojtys EM. Anterior cruciate ligament injuries in the female athlete: Potential risk factors. Clinical Orthopaedics and Related Research (1976-2007). 2000; 372:50-63. [DOI:10.1097/00003086-200003000-00007] [PMID]

[13] Olsen OE, Myklebust G, Engebretsen L, Bahr R. Injury mechanisms for anterior cruciate ligament injuries in team handball: A systematic video analysis. The American Journal of Sports Medicine. 2004; 32(4):1002-12. [DOI:10.1177/0363546503261724] [PMID]

[14] McLaren N, Fleming P, Forrester S. Artificial grass: A conceptual model for degradation in performance. Procedia Engineering. 2012; 34:831-6. [DOI:10.1016/j.proeng.2012.04.142]

[15] Severn KA, Fleming PR, Dixon N. Science of synthetic turf surfaces: Player-surface interactions. Sports Technology. 2010; 3(1):13-25. [D Ol:10.1080/19346190.2010.504279]

[16] Arianasab H, Mohammadipour F, Amiri-Khorasani M. Comparison of knee joint kinematics during a countermovement jump among different sports surfaces in male soccer players. Science and Medicine in Football. 2017; 1(1):74-9. [DOI:10.1080/02640414.2016.125481 1]

[17] Lyle MA, Valero-Cuevas FJ, Gregor RJ, Powers CM. Control of dynamic foot-ground interactions in male and female soccer athletes: Females exhibit reduced dexterity and higher limb stiffness during landing. Journal of Biomechanics. 2014; 47(2):512-7. [DOI:10.1016/j.jbiomech.2013.10.038] [PMID] [PMCID]

[18] Broström L. Sprained ankles. V. Treatment and prognosis in recent ligament ruptures. Acta chirurgica Scandinavica. 1966; 132(5):537-50. 
[19] Cawley PW, Heidt Jr RS, Scranton Jr PE, Losse Jr GM, Howard Jr ME. Physiologic axial load, frictional resistance, and the football shoesurface interface. Foot \& Ankle International. 2003; 24(7):551-6. [D OI:10.1177/107110070302400705] [PMID]

[20] Kristenson K, Bjørneboe J, Waldén M, Andersen T, Ekstrand J, Hägglund $M$. The Nordic football injury audit: Higher injury rates for professional football clubs with third-generation artificial turf at their home venue. British Journal of Sports Medicine. 2014; 48(7). [DOI:10.1136/bjsports-2014-093494.166]

[21] Lanzetti R, Ciompi A, Lupariello D, Guzzini M, De Carli A, Ferretti A. Safety of third-generation artificial turf in male elite professional soccer players in Italian major league. Scandinavian Journal of Medicine \& Science in Sports. 2017; 27(4):435-9. [DOI:10.1111/ sms.12654] [PMID]

[22] Soligard T, Bahr R, Andersen TE. Injury risk on artificial turf and grass in youth tournament football. Scandinavian Journal of Medicine \& Science in Sports. 2012; 22(3):356-61. [DOI:10.1111/j.16000838.2010.01174.x] [PMID]

[23] Havens KL and Sigward SM. Whole body postural mechanics of running turn maneuvers. Gait \& Posture, 42(3):240-5.

[24] Hardin EC, Van Den Bogert AJ, Hamill J. Kinematic adaptations during running: Effects of footwear, surface, and duration. Medicine $\&$ Science in Sports \& Exercise. 2004; 36(5):838-44. [DOI:10.1249/01. MSS.0000126605.65966.40] [PMID]

[25] Silverman AK, Wilken JM, Sinitski EH, Neptune RR. Wholebody angular momentum in incline and decline walking. Journal of Biomechanics. 2012; 45(6):965-71. [DOI:10.1016/j.jbiomech.2012.01.012] [PMID]

[26] Burillo P, Gallardo L, Felipe JL, Gallardo AM. Artificial turf surfaces: Perception of safety, sporting feature, satisfaction and preference of football users. European Journal of Sport Science. 2014 14(sup1):S437-S47. [DOI:10.1080/17461391.2012.713005] [PMID]

[27] Zanetti EM. Amateur football game on artificial turf: Players' perceptions. Applied Ergonomics. 2009; 40(3):485-90. [DOI:10.1016/j. apergo.2008.09.007] [PMID]

[28] Bianco A, Spedicato M, Petrucci M, Messina G, Thomas E, Sahin $\mathrm{FN}$, et al. A prospective analysis of the injury incidence of young male professional football players on artificial turf. Asian Journal of Sports Medicine. 2016; 7(1):e28425. [DOI:10.5812/asjsm.28425] [PMID] [PMCID]

[29] O'Kane JW, Gray KE, Levy MR, Neradilek M, Tencer AF, Polissar NL, et al. Shoe and field surface risk factors for acute lower extremity injuries among female youth soccer players. Clinical Journal of Sport Medicine: Official Journal of the Canadian Academy of Sport Medicine. 2016; 26(3):245-50. [DOI:10.1097/JSM.0000000000000236] [PMID] [PMCID]

[30] Meyers MC. Incidence, mechanisms, and severity of matchrelated collegiate women's soccer injuries on FieldTurf and natural grass surfaces: A 5-year prospective study. The American Journal of Sports Medicine. 2013; 41(10):2409-20. [DOI:10.1177/0363546513498994] [PMID]

[31] Brachet P, Blackburn S, Nicol AC, Walker C. Body and limb accelerations during football activities on artificial turfs. In Proceedings of the International Society of Biomechanics XIXth Congress; 200306 11 Jun.https://strathprints.strath.ac.uk/id/eprint/8360

[32] Scranton Jr PE, Whitesel JP, Powell JW, Dormer SG, Heidt Jr RS, Losse $\mathrm{G}$, et al. A review of selected noncontact anterior cruciate ligament injuries in the National Football League. Foot \& Ankle International. 1997; 18(12):772-6. [DOI:10.1177/1071100797018012 04] [PMID]

[33] Strutzenberger G, Cao H-M, Koussev J, Potthast W, Irwin G. Effect of turf on the cutting movement of female football players. Journal of Sport and Health Science. 2014; 3(4):314-9. [DOI:10.1016/j. jshs.2014.07.004]

[34] Meyers MC. Incidence, mechanisms, and severity of game-related college football injuries on Field Turf versus natural grass: A 3-year prospective study. The American Journal of Sports Medicine. 2014; 38(4):687-97. [DOI:10.1177/0363546509352464] [PMID]

[35] McNair PJ, Hewson DJ, Dombroski E, Stanley SN. Stiffness and passive peak force changes at the ankle joint: The effect of different joint angular velocities. Clinical Biomechanics. 2002; 17(7):536-40. [DOI:10.1016/S0268-0033(02)00062-1]

[36] Peppelman M, van den Eijnde WA, Langewouters AM, Weghuis $\mathrm{MO}$, van Erp PE. The potential of the skin as a readout system to test artificial turf systems: Clinical and immunohistological effects of a sliding on natural grass and artificial turf. International Journal of Sports Medicine. 2013; 34(09):783-8. [DOI:10.1055/s-0032-1331173] [PMID]

[37] Teixeira-Salmela LF, Nadeau S, Milot M-H, Gravel D, Requião LF. Effects of cadence on energy generation and absorption at lower extremity joints during gait. Clinical Biomechanics. 2008; 23(6):76978. [DOI:10.1016/j.clinbiomech.2008.02.007] [PMID] 